\title{
Making their decisions for prostate cancer treatment: Patients' experiences and preferences related to process
}

\author{
Deb Feldman-Stewart, $\mathrm{PhD}^{1}$; Christine Tong, $\mathrm{MA}^{1}$; Michael Brundage, MD, MSc ${ }^{1}$; Jackie \\ Bender, $\mathrm{PhD}^{2}$; John Robinson, $\mathrm{PhD}^{3}$ \\ ${ }^{1}$ Division of Cancer Care and Epidemiology, Cancer Research Institute, Queen's University, Kingston, \\ ON; 2ELLICSR Health, Wellness \& Cancer Survivorship Centre, Department of Supportive Care, University Health \\ Network, Toronto, ON; ${ }^{3}$ Department of Psychosocial and Rehabilitation Oncology, Tom Baker Cancer Centre, \\ Calgary, AB; Canada
}

Acknowledgements: We would like to thank Robert C. Hornik and Rebekah H. Nagler for their immediate willingness to share their survey and details of their methods with us. We would also like to thank the Cancer Registries of British Columbia, Alberta, Saskatchewan, and Ontario for their assistance in this study. This work was awarded by Prostate Cancer Canada and is proudly funded by Movember.

Cite as: Can Urol Assoc J 2018 May 28; Epub ahead of print. http://dx.doi.org/10.5489/cuaj.5113

Published online May 28, 2018

***

Abstract

Introduction: We sought to determine the experiences and preferences of prostate cancer patients related to the process of making their treatment decisions, and to the use of decision support.

Methods: Population surveys were conducted in four Canadian provinces in 2014-2015. Each provincial cancer registry mailed surveys to a random sample of their prostate cancer patients diagnosed in late 2012. Three registries' response rates were 46-55\%; the fourth used a different recruiting strategy, producing a response rate of $13 \%$ (total $n=1366$ ).

Results: Overall, 90\% $(n=1113)$ of respondents reported that they were involved in their treatment decisions. Twenty-three percent $(n=247)$ of respondents wanted more help with the decision than they received and 52\% of them $(n=128)$ reported feeling well-informed. Only 51\% $(\mathrm{n}=653)$ of all respondents reported receiving any decision support, but an additional 34\% $(n=437)$ would want to if they were aware of its existence. A quarter $(25 \%, n=316)$ of respondents found it helpful to use a decision aid, a type of decision support that provides assistance to decision processes and provides information, but $64 \%(n=828)$ reported never having heard of decision aids; $26 \%(n=176)$ of those who had never heard of decision aids 
wanted more help with the decision than they received compared to $13 \%(n=36)$ of those who had used a decision aid.

Conclusions: The majority of respondents wanted to participate in their treatment decisions, but a portion wanted more help than they received. Half of those who wanted more help felt wellinformed, thus, needed support beyond information. Decision aids have potential to provide information and support to the decision process.

\section{Introduction}

Prostate cancer has the highest incidence among new cancer diagnoses in Canadian men, accounting for approximately $21 \%$ of new diagnoses, or 20,700 new prostate cancer diagnoses in 2017. ${ }^{1}$ While there are few studies of the experiences of these patients at the level of the population, one Finnish population study determined that the patient's experiences around diagnosis and treatment selection can have long-lasting impact on his psychological well-being. ${ }^{2}$

A recent population study of Canadian prostate cancer patients found that $90 \%$ of respondents wanted to participate in making their treatment decision ${ }^{3}$. For those patients, information provision is required but may not be sufficient for effective decision support. Beyond obtaining information, deliberative decision making includes processes such as identifying relevant values that are important to the individual, and integrating values and preferences which may be in conflict in order to arrive at a single preferred option. ${ }^{4}$

Decision aids (DA) are tools that provide support to deliberative decision processes in addition to providing information relevant to the decision. ${ }^{5}$ A Cochrane review of randomized controlled trials (RCTs) of decision aids found that, compared to usual care, using decision aids generally resulted in lower decisional conflict, including specifically lower conflict related to feeling unclear about personal values. ${ }^{5}$

A 2015 systematic review of RCTs assessing DAs for localized prostate cancer treatment choice found that the DA's varied considerably in underlying theoretical frameworks, formats, and method of delivery, with most being designed to be used by patients outside the medical encounter. ${ }^{6}$ Only four of the studies assessed acceptability to patients, and they all reported high levels of acceptability among their study participants. A 2015 American national survey of urologists and radiation oncologists found that although most respondents had some familiarity with DAs, only 35.5\% used one for localized prostate cancer in their practice. ${ }^{7}$ Thus, the limited studies suggest that patients find DAs helpful and acceptable but the specialists are not often using them in their clinical practices.

The RCTs suggest that decision support requires more than information provision alone: an RCT that compared outcomes of patients who used a DA to those who received only structured information found that patients who used the DA felt better-prepared to make their decisions with their doctors, and experienced less regret one year after the decision was made, compared to patients who received only the information component of the aid. ${ }^{8}$ But we could find no population-based studies that clearly corroborate that result on a larger scale. One 
population-based study of the quality of care of prostate cancer patients that found that care reported to include "discussion of all treatment options" was associated with reduced patientreported regret. ${ }^{9}$ Little further information is provided about the decision making processes.

We conducted a large population-based survey addressing the needs, experiences, and preferences of prostate cancer patients from the time of their diagnosis to after their treatment. We previously reported the patients' experiences and preferences around information sources, in the time just after diagnosis. ${ }^{3}$ In this paper, we focus on the theme of decision making and report patients' experiences and preferences making their initial treatment decision.

The objectives addressed in this report were to describe aspects of how prostate cancer patients' initial treatment decision was made and how they felt about it, along with their experiences with and preferences for additional decision support.

\section{Methods}

Population surveys of prostate cancer patients were conducted in four provinces, British Columbia (BC), Alberta (AB), Saskatchewan (SK) and Ontario (ON), in 2014-15 using their respective provincial cancer registries. We sought to obtain responses from $10 \%$ of the provincial patients. The expected response rate in the survey was 30\%, thus, to achieve responses from $10 \%$ of the population of men diagnosed in our target interval, each registry invited a random selection of 55-60\% of men diagnosed with prostate cancer in the last half of 2012 in their registry to participate in the study. That year was selected because we wanted memories of the diagnosis experience to be as "fresh" as possible, and 2012 was the latest year that all registries had complete and clean data. To keep the recall time (and hence associated consequences) as similar as possible in the surveyed group while having a large enough group of men to draw from, we restricted the diagnosis time to the last six months of 2012.

Three registries (BC, AB, SK) used an “opt-out” recruiting strategy, providing a cover letter introducing the study with the survey, making clear that completion was optional. The fourth registry (ON) used an "opt-in” strategy, providing a letter introducing the study and required the recipient to phone the registry to volunteer, for the survey to be sent. Thus, each province identified as random sample of men to invite to participate in the survey, and the opt-in or opt-out strategy was implemented in the letter of invitation. We chose to use random selection as it is expected that the distribution of characteristics of the population would be captured in the sample. Survey packages in all provinces included the survey, and an addressed, stamped envelope in which to return the completed survey. After four weeks, a second survey package was sent to non-respondents. Response rates for the opt-out provinces were $46 \%-55 \%$, and for the opt-in province was 13\% (total N=1366). Ethics approvals were secured in each province.

The survey had been developed by the authors and their advisors, then assessed through cognitive interviews with patients selected to represent a range of characteristics. The interviews continued until the stopping rule of no new confusions, misunderstandings or questions emerged from two consecutive interviews. The final survey focussed on a number of themes, each 
addressed in separate section of the survey. The sections were: information and decision making just after diagnosis, current needs, internet use, what they would like to see in a website for men with prostate cancer and their families, and background information. This report is focussed on decision support just after diagnosis. The questions, as they appeared in the survey, and their response options are shown in the results.

\section{Results}

Table 1 shows respondents' demographic and health characteristics, with the number and percentages of those who responded to the question. As the table shows, approximately $90 \%$ of respondents were either in follow-up after treatment or being followed in active surveillance, and less than $10 \%$ had experienced a recurrence or metastatic disease. Almost all respondents reported that their overall health was good or very good.

Table 2 shows the six survey questions related to decision making with their response options and the response distributions to each of the first five. The response distribution to the sixth question is shown in Figure 1. As can be seen in Table 2 Q1, 90\% ( $\mathrm{n}=1135)$ of respondents reported that they were involved in making their decisions, either alone or with others, and about $10 \%(\mathrm{n}=118)$ reported that their doctors made their decisions for them. The distributions of actual roles (Q1) and desired roles (Q2) appear almost identical. However, a direct comparison of each respondent's reported actual to his desired role revealed that $21 \%(\mathrm{n}=256)$ of respondents wanted a different role than happened: $12 \%(\mathrm{n}=140)$ wanted other people to be more involved, and $9 \%(n=113)$ wanted others to be less involved. The discordances included $4 \%(n=47)$ who wanted the doctor to make the decision but had not, and $3 \%(\mathrm{n}=44)$ who reported the doctor did make the decision but the respondent did not want them to.

Desire for decision support

While only $4 \%$ of respondents $(n=43)$ reported that they were not satisfied with their decision, 23\% ( $\mathrm{n}=251$ ) reported wanting more help with their decision than they received (Table 2 Q3). Interestingly, of the 247 who wanted more help with the decision and identified how informed they felt, 128 of them (52\%) reported feeling well informed. 34\% ( $n=437)$ who did not receive any decision support would have been interested in using decision support if they had known about it.

Table 3 shows the number of respondents who received each treatment (either alone or in combination) and the percentage of each who wanted more help with the decision. As can be seen, that percentage is relatively similar across treatment groups. Further, approximately half of each group that wanted more help with their decisions felt well informed (Table 3).

Finally, the number of specialists that a patient saw was not related to whether or not they wanted more help with the decision: $20 \%$ of those who saw only a urologist compared to $17 \%$ who saw both a urologist and a radiation oncologist, and 19\% of those who saw both a urologist and a medical oncologist wanted more help.

Decision support received 
Overall, 51\% of respondents used some type of decision support including decision aids, information pamphlets, books, classes etc (Table 2 Q5). Using decision support specifically designed to help decision processes, $25 \%$ of respondents had used a decision aid and found it helpful, while 3\% used one and did not find it helpful (Table2 Q4). However, 65\% of respondents had not heard of decision aids.

Table 4 shows, for different levels of experience with a decision aid, the percentage of respondents who wanted more help with the decision. As can be seen, only $13 \%$ of the 267 who used a decision aid (including both those who found it helpful and those who did not) wanted more help with the decision compared to $26 \%$ of the 670 who never heard of decision aids before.

Figure 1 shows respondents' recommendations for timing of offering decision support. As it shows, two points in the early care trajectory were selected almost equally often: $39 \%$ recommend it be offered after initial visits to all specialists before the decision is made, and 33\% at the first visit with the urologist.

\section{Provincial Comparisons}

Table 5 shows the four provinces' response distributions to decision role, wanting more help with the decision, experience with decision support, and recommended times for decision support to be offered. As can been seen in the table, each of the distributions shows percentages that are very similar across provinces, including that about $90 \%$ of our respondents in each province reported participating in making their decision with only about $10 \%$ in each province reporting that their doctors made their decisions.

\section{Discussion}

Our study found that the majority of our respondents wanted to be involved in making their treatment decisions but approximately one-quarter of them wanted more help with the decision than they received. The vast majority of them (85\%) would like to use some form of decision support.

The fact that approximately one-half of those who wanted more decision help but also felt well-informed, suggests that the decision support they need is not likely easily addressed by providing them with more information. This result corroborates the suggestion that information provision is necessary but sometimes not sufficient support for patients' decision making.

We also found that the percentage of respondents who wanted more help with their decisions was not associated with the number of specialists seen. This result is in contrast to our earlier finding that a larger percentage of our respondents who saw both a urologist and a radiation oncologist felt well informed compared to the percentage of those who saw only a urologist. $^{3}$ The difference in these two findings further emphasizes the distinction between being informed and making the decision.

The distinction between providing information and providing decision support raises questions about how to provide additional decision support. Among the patients who feel well 
informed but want more help with the decision are those who need assistance with specific deliberative decision processes, such as identifying factors important to the individual's decision. "Values clarification", offered in patient decision aids, provides support for decision processes. ${ }^{10}$ Because decision aids also include information about the disease and its potential treatments ${ }^{11}$ these tools would also likely help respondents who did not feel well informed. Thus, decision aids with values clarification exercises are tools that are likely to be helpful to more patients who want more help with decision making than other types of decision support.

The percentage of respondents who never heard of decision aids and wanted more help with the decision (26\%) was twice the percentage of respondents who had used a decision aid and still wanted more help with the decision (13\%). That suggests that using a decision aid has the potential to substantially reduce the percentage of patients who want help with the decision. We note that the $28 \%$ of our respondents who reported using a DA is in line with the $35 \%$ of American radiation oncologists and urologists who reported using DAs in their clinical practice.

A small percentage of respondents (3\%) used a decision aid but did not find it very helpful. A patient could find a decision aid not helpful because his particular needs are unique.

It is also possible that a particular decision aid is not very effective. A 2006 review of decision aids identified 11 aids that addressed the decision about treatment of prostate cancer, ${ }^{12}$ and a 2015 review of decision aids specifically for prostate cancer treatment that identified 14 DAs. $^{6}$ There are many ways the aids can differ from one another including their design, intended goals, organization, amount of information, and types of values clarification. They also differ in how they have been evaluated. Because decision aids differ from one another, it is helpful to check for evidence of a particular decision aid's efficacy before it is integrated into practice.

In addition to differences in design amongst decision aids, there are also differences in how they are intended to be implemented: some are intended to be used in the consultation with the doctor (e.g., ${ }^{13}$ ) and others intended to be used by the patient alone, designed to help them determine their preferences, so that they can then be discussed with the doctor (e.g. ${ }^{14}$ ). As we reported recently, our respondents indicated that actually running out of time with their doctors or being worried about taking up too much time were top barriers to their obtaining information from their doctors. The style of decision aids designed for patients to use on their own avoids the concerns about doctors' time. Further, if the doctor directs the patient to the decision aid, the patient can be assured about its quality and its relevance to his situation, two concerns that patients have identified regarding use of public information sources. ${ }^{3}$

The point in the care trajectory recommended for decision support by our respondents varied considerably: over one-third suggested decision support be offered after the visits with both the urologist and the radiation oncologist, almost another third recommended it be offered at the first visit to the urologist, and a few recommended that it be offered even before that first meeting with the urologist. This range in recommendations suggests that the DA is best offered to the patient via a flexible system so that the individual can access it when he wants to but, for 
the patient to be able to do so, he would need to be made aware of the opportunity to use it early in the care path.

The need for frequent updating of the information on prostate cancer and its treatments makes it appealing to offer decision aids electronically. However, as we reported recently, onethird our respondents made clear that they do not want to use the internet, and approximately two thirds would like to receive information both on the internet and on paper. ${ }^{3}$ This medium preference suggests that decision aids too, would be most effectively offered to this population in both media. To achieve the benefits of easy updating but still offer it in both media, one possibility is that the internet support could be printed off by a third party to make available to the patient and his family as needed.

Our study was conducted in four Canadian provinces which have differing healthcare systems and recruiting strategies. Despite these provincial differences, response distributions across the provinces were remarkably consistent. The similarity suggests that the data are valid and that the random sampling of each provincial population was effective. Further, because we have found no provincial differences in responses to the decision-related questions, and the 4 provinces we surveyed include $67 \%$ of Canada's prostate cancer patients, ${ }^{1}$ it could be reasonable to expect the results to be true of the other provinces.

We recognize that our study has particular limitations. It is possible that a higher proportion of non-responders are not interested in issues related to information and decision support than of the responders. Thus, we need to be cautious about generalizing our results to all prostate cancer patients. We suggest, however, that our responders are large enough numbers in of themselves that offering decision support outside the consultations, and in fact decision aids, would be helpful and appreciated by many patients.

In conclusion, our results suggest that a large majority of prostate cancer patients want to be involved in their treatment decision and that a portion of them want more support in that process than they received. Decision aids would help patients with particular decision processes that can be challenging, as well as provide clear information. Such aids designed for the patient to use outside the consultation could address the patients' decision making concerns without taking additional consultation time. Further, making decision aids available on the internet, in printable versions that can be offered separately, would be a strategy that allows for flexible access, relatively easy updating, and yet still provide the support in the medium that the individual wants. 


\section{References}

1. Canadian Cancer Society, Statistics Canada, Public Health Agency of Canada, Provincial/Territorial Cancer Agencies. Canadian Cancer Statistics 2017..

2. Lehto US, Helander S, Taari K, Aromaa A. Patient experiences at diagnosis and psychological well-being in prostate cancer: A Finnish national survey. Eur J Oncol Nurs 2015;19:220-229.

3. Feldman-Stewart D, Tong C, Brundage MD, Bender J, Robinson J. Prostate cancer patients' experience and preferences for acquiring information early in their care. Can Urol Assoc J. In press.

4. Svenson O. Process descriptions of decision making. Organ BehavHum Perf 1979;23:86112.

5. Stacey D, Legare F, Col NF et al. Decision aids for people facing health treatment or screening decisions [Systematic Review]. Cochrane Db Syst Rev 2014;1.

6. Violette P.D., Agoritsas T, Alexander P. et al. Decision aids for localized prostate cancer treatment choice: Systematic review and meta-analysis. CA: Cancer J Clin 2015;65:239251.

7. Wang E.H., Gross C.P., Tilburt J.C. et al. Shared decision making and use of decision aids for localized prostate cancer: Perception from radiation oncologists and urologists. JAMA Intern Med 2015;175:792-799.

8. Feldman-Stewart D, Tong C, Siemens R et al. The impact of explicit values clarification exercises in a patient decision aid emerges after the decision is actually made: evidence from a randomized controlled trial. Med Decis Making 2012;32(4):616-626.

9. Holmes JA, Bensen JT, Mohler JL, Song L, Mishel MH, Chen RC. Quality of care received and patient-reported regret in prostate cancer: Analysis of a population-based prospective cohort. Cancer 2017;123:138-43.

10. Fagerlin A, Pignone M, Abhyankar P et al. Clarifying values: An updated review. BMC Med Inform Decis 2013;13(Suppl 2):S8.

11. Feldman-Stewart D, O'Brien MA, Clayman ML et al. Providing information about options in patient decision aids. BMC Med Inform Decis 2013;13(Suppl 2):S4.

12. Feldman-Stewart D, Brennenstuhl S, McIsaac K et al. A systematic review of information in decision aids. Health Expect 2007;10(1):46-61.

13. Dolan JG, Frisina S. Randomized controlled trial of a patient decision aid for colorectal cancer screening. Med Decis Making 2002;22(2):125-139.

14. Feldman-Stewart D, Brundage MD, Van Manen L, Svenson O. Patient-focussed decisionmaking in early-stage prostate cancer: Insights from a cognitively based decision aid. Health Expect 2004;7:126-141. 


\section{Figures and Tables}

Fig. 1. Respondents' recommendations for when decision support should be offered during care trajectory.

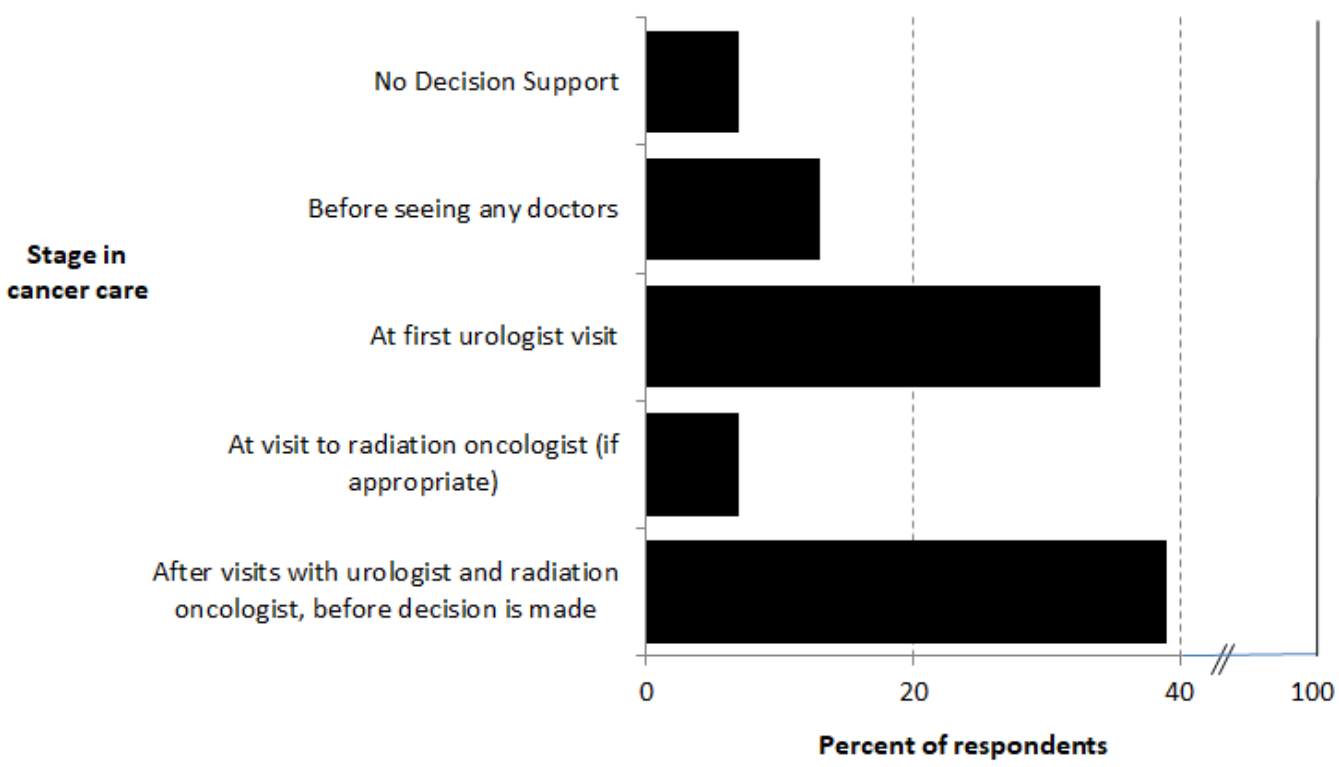




\begin{tabular}{|c|c|}
\hline Demographic characteristics (options) & Overall \\
\hline Age & Mean $(n=1320): 69$ years $(S D=8.2)$ \\
\hline \multicolumn{2}{|l|}{ Partnership status } \\
\hline With partner & $86 \%(n=1130)$ \\
\hline Without partner & $13.6 \%(n=170)$ \\
\hline \multicolumn{2}{|l|}{ Sexual orientation } \\
\hline Gay & $1.4 \%(n=17)$ \\
\hline Heterosexual & $98 \%(n=1201)$ \\
\hline Bisexual & $0.7 \%(n=8)$ \\
\hline \multicolumn{2}{|l|}{ Education: Highest level completed } \\
\hline Primary & $7.2 \%(n=94)$ \\
\hline Secondary & $26.3 \%(n=345)$ \\
\hline College/diploma & $33.3 \%(n=437)$ \\
\hline University & $33.2 \%(n=436)$ \\
\hline \multicolumn{2}{|l|}{ Residence } \\
\hline Urban/suburban & $63.1 \%(n=834)$ \\
\hline Town/rural & $36.9 \%(n=487)$ \\
\hline \multicolumn{2}{|l|}{ Annual income } \\
\hline$\leq \$ 20 \mathrm{~K}$ & $7.4 \%(n=90)$ \\
\hline$>\$ 20$ to $\leq \$ 40 \mathrm{~K}$ & $21.3 \%(n=257)$ \\
\hline$>\$ 40 \mathrm{~K}$ to $\leq \$ 80 \mathrm{~K}$ & $37.4 \%(n=454)$ \\
\hline$>\$ 80 \mathrm{~K}$ & $34.1 \%(n=414)$ \\
\hline Health characteristics & Overall \\
\hline \multicolumn{2}{|l|}{ Cancer journey status } \\
\hline On active surveillance or watchful waiting & $25.6 \%(n=292)$ \\
\hline $\begin{array}{l}\text { Recently finished treatment not started followup } \\
\text { visits }\end{array}$ & $4.1 \%(n=47)$ \\
\hline Followup after treatment & $63.1 \%(n=719)$ \\
\hline Getting treatment for recurrent cancer & $3.2 \%(n=36)$ \\
\hline Finished treatment for recurrent cancer ( $<3$ months) & $1.9 \%(n=22)$ \\
\hline Receiving treatment for metastatic disease & $2.0 \%(n=23)$ \\
\hline \multicolumn{2}{|l|}{ Overall health } \\
\hline Very good/good & $93.7 \%(n=1233)$ \\
\hline Poor/very poor & $6.3 \%(n=83)$ \\
\hline
\end{tabular}


Table 2. Decision-making questions (Q1-Q6), their response options, and response distributions

Decision role

\begin{tabular}{|c|c|c|}
\hline & $\begin{array}{l}\text { Q1. Who made the } \\
\text { decision about your } \\
\text { prostate cancer } \\
\text { treatment? } \\
\text { I made the decision... }\end{array}$ & $\begin{array}{l}\text { Q2. Who did you want to make } \\
\text { the decision about your prostate } \\
\text { cancer treatment? } \\
\text { I WANTED to make the } \\
\text { decision.. }\end{array}$ \\
\hline By myself & $12 \%(n=154)$ & $13 \%(n=167)$ \\
\hline With my doctor & $32 \%(n=404)$ & $30 \%(n=377)$ \\
\hline With my family & $8 \%(n=104)$ & $7 \%(n=90)$ \\
\hline $\begin{array}{l}\text { With my family and my } \\
\text { doctor }\end{array}$ & $38 \%(n=473)$ & $40 \%(n=516)$ \\
\hline $\begin{array}{l}\text { My doctor made the decision } \\
\text { after considering my opinion }\end{array}$ & $9.5 \%(n=118)$ & $8 \%(n=122)$ \\
\hline $\begin{array}{l}\text { A family member or caregiver } \\
\text { made the decision }\end{array}$ & $0 \%(n=3)$ & $0 \%(n=4)$ \\
\hline
\end{tabular}

Q3. Decision satisfaction: How much do you agree or disagree with each of the following statements?

\begin{tabular}{|l|c|c|c|}
\hline I would have liked more help with my decision & $50 \%(\mathrm{n}=529)$ & $27 \%(\mathrm{n}=287)$ & $23 \%(\mathrm{n}=251)$ \\
\hline
\end{tabular}

Q4. "Decision aids" are tools to help a patient figure out which treatment he prefers....provides step-by-step help in figuring out what is important to your decision, and in weighing the pros and cons of each option. Which situation best describes what you know about decision aids, your desire and experience using one? ${ }^{1}$

\begin{tabular}{|l|c|}
\hline I have never heard of decision aids before & $65 \%(n=828)$ \\
\hline I have heard of decision aids before but did not want to use one & $5 \%(n=65)$ \\
\hline $\begin{array}{l}\text { I wanted to use a decision aid but did not know how to get access to one/ } \\
\text { tried to access one but was unsuccessful }\end{array}$ & $3 \%(n=38)$ \\
\hline I used a decision aid but it was not very helpful & $3 \%(n=19)$ \\
\hline I used a decision aid and it was very helpful & $25 \%(n=316)$ \\
\hline
\end{tabular}

Q5. “Decision support” refers to all types of products meant to help patients understand their situations and to participate in making decision about their healthcare...includes decision aids, information pamphlets...Did you use any type of decision support? ${ }^{1}$

\begin{tabular}{l|l} 
Yes & $51 \%(\mathrm{n}=653)$
\end{tabular}

\begin{tabular}{|l|l}
\hline No, but I would have been interested & $34 \%(\mathrm{n}=437)$ \\
\hline
\end{tabular}

\begin{tabular}{|l|l}
\hline No, and I would not have been interested & $14 \%(n=179)$
\end{tabular}

Q6. If a patient like you were offered decision support, when do you think having the support would be most helpful? ${ }^{1}$ (Response distribution shown in Fig. 1)

Before meeting with my doctor(s) 
At my first visit with my urologist, either with the doctor or nurse At my first visit with my radiation oncologist, either with the doctor or nurse

After my first visits with my urologist and radiation oncologist but before the treatment

decision was made

I would not want decision support

${ }^{1}$ The question was followed with the instruction: Please check BEST response.

\begin{tabular}{|c|c|c|c|}
\hline \multirow[b]{2}{*}{ Treatment } & \multicolumn{3}{|c|}{$\begin{array}{l}\text { Respondents who received the treatment } \\
\text { (alone or in combination) }\end{array}$} \\
\hline & $\begin{array}{l}\text { Total number } \\
\text { who received } \\
\text { the treatment }\end{array}$ & $\begin{array}{c}\text { \% who wanted more } \\
\text { help with decision } \\
\text { of those who received } \\
\text { the treatment }\end{array}$ & $\begin{array}{l}\text { \% who wanted more } \\
\text { help with decision and } \\
\text { felt well-informed } \\
\text { of those who wanted } \\
\text { more help with decision }\end{array}$ \\
\hline Surgery & 467 & $28 \%(n=130)$ & $55 \%(n=71)$ \\
\hline External beam radiation therapy & 339 & $20 \%(n=67)$ & $37 \%(n=25)$ \\
\hline Brachytherapy & 194 & $16 \%(n=32)$ & $53 \%(n=17)$ \\
\hline $\begin{array}{l}\text { Active surveillance (no treatment } \\
\text { received unless the cancer becomes } \\
\text { active, they try to cure the disease }{ }^{*} \text { ) }\end{array}$ & 181 & $20 \%(n=36)$ & $50 \%(n=18)$ \\
\hline $\begin{array}{l}\text { Hormone therapy or androgen- } \\
\text { deprivation therapy }\end{array}$ & 279 & $24 \%(n=66)$ & $36 \%(n=24)$ \\
\hline Chemotherapy & 21 & $19 \%(n=4)$ & $50 \%(n=2)$ \\
\hline $\begin{array}{l}\text { Watchful waiting (no treatment } \\
\text { received unless the cancer causes } \\
\text { symptoms, then only treat symptoms }{ }^{*} \text { ) }\end{array}$ & 118 & $19 \%(n=23)$ & $48 \%(n=11)$ \\
\hline
\end{tabular}

${ }^{*}$ Definition provided in survey 
Table 4. The percentage of respondents at each level of experience with decision aids who wanted more help with their decision

\begin{tabular}{|c|c|c|}
\hline Experience with decision aids & $\begin{array}{c}\text { Number } \\
\text { of } \\
\text { responses }\end{array}$ & $\begin{array}{c}\% \text { of those } \\
\text { responses who } \\
\text { wanted more } \\
\text { help with the } \\
\text { decision }\end{array}$ \\
\hline I have never heard of decision aids before & 670 & $26 \%(n=176)$ \\
\hline $\begin{array}{l}\text { I have heard of decision aids before but did not want to use } \\
\text { one }\end{array}$ & 54 & $11 \%(n=6)$ \\
\hline $\begin{array}{l}\text { I wanted to use a decision aid but did not know how to get } \\
\text { access to one/ tried to access one but was unsuccessful }\end{array}$ & 35 & $63 \%(n=22)$ \\
\hline I used a decision aid and it was helpful/not helpful & 267 & $13 \%(n=36)$ \\
\hline
\end{tabular}

\section{Table 5. Provincial comparisons}

\section{Decision role}

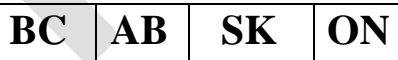

\begin{tabular}{|c|c|c|c|c|}
\hline $\begin{array}{l}\text { I made the decision by myself/with doctor/with family/with family and } \\
\text { doctor }\end{array}$ & $91 \%$ & $89 \%$ & $92 \%$ & $90 \%$ \\
\hline My doctor made my decision after considering my opinion & $9 \%$ & $11 \%$ & $8 \%$ & $10 \%$ \\
\hline More help with decision & & & & \\
\hline $\begin{array}{l}\text { I would have like more help with my decision “Agree” or 'Strongly } \\
\text { agree” }\end{array}$ & $21 \%$ & $26 \%$ & $21 \%$ & $26 \%$ \\
\hline
\end{tabular}

\section{Experience with decision support}

\begin{tabular}{|l|l|l|l|l|}
\hline I used some form of “decision support” & $49 \%$ & $51 \%$ & $45 \%$ & $57 \%$ \\
\hline Never heard of “decision aids” & $63 \%$ & $66 \%$ & $71 \%$ & $65 \%$ \\
\hline I used a decision aid and it was very helpful & $27 \%$ & $24 \%$ & $20 \%$ & $25 \%$ \\
\hline Most helpful time to offer decision support & \multicolumn{4}{|l|}{} \\
\hline At first visit with urologist & $33 \%$ & $33 \%$ & $40 \%$ & $32 \%$ \\
\hline After first visit with urologist and radiation oncologist & $41 \%$ & $42 \%$ & $30 \%$ & $41 \%$ \\
\hline
\end{tabular}

